\title{
Interventions to increase migrants' care-seeking behaviour for stigmatised conditions: a scoping review
}

\author{
Vanessa Place ${ }^{1}$ Benjamin Nabb ${ }^{1} \cdot$ Karima Viksten Assel $^{1,2} \cdot$ Sofie Bäärnhielm ${ }^{1,2} \cdot$ Christina Dalman $^{1,3}$. \\ Anna-Clara Hollander ${ }^{1,4}$ (D)
}

Received: 21 August 2020 / Accepted: 10 March 2021 / Published online: 29 March 2021

(c) The Author(s) 2021

\begin{abstract}
Background Despite availability of effective treatments, migrants in high-income countries seek care for conditions associated with stigma to a lower extent than the rest of the population. We conducted a scoping review to map the literature on interventions to increase migrants' care-seeking behaviour in high-income countries for stigmatised conditions.

Main body of the abstract: We searched 15 electronic databases and journals, hand-searched references and citations, to identify studies on interventions to increase migrants' care-seeking in high-income countries for stigmatised conditions. We applied language restrictions for English and Swedish, and searched the full time period up to 5 July 2019. Our primary outcome of interest was care utilisation.

Results 5447 records were identified in the literature searches. We identified 16 eligible studies, all from North America, that reported interventions to increase migrants' care-seeking behaviour for hepatitis $\mathrm{B}(n=1)$ and mental health $(n=15)$. Three approaches were identified: health communication $(n=10)$, support groups $(n=2)$, and primary care-based approaches $(n=4)$. There was a general trend towards community-based interventions tailored to individual migrant groups. Significant gaps were identified in the literature, including studies conducted in Europe and studies including men or children. Furthermore, the choice of study designs introduced significant bias that prevented accurate conclusions on intervention effectiveness.

Conclusion The available evidence on interventions to increase migrants' in high-income countries care-seeking behaviour for stigmatised conditions is limited in scope and quality. Future research, using reliable study designs, is needed to fill the remaining gaps and to boost the scope and reliability of the evidence.
\end{abstract}

Keywords Migrants $\cdot$ High-income countries $\cdot$ Stigma $\cdot$ Scoping review $\cdot$ Interventions to increase care-seeking behaviour . Mental health $\cdot$ TB $\cdot$ HIV $\cdot$ Hepatitis $\cdot$ Care-seeking

Anna-Clara Hollander

anna-clara.hollander@ki.se

Karolinska Institutet, Stockholm, Sweden

2 Transkulturellt Centrum, Stockholm, Sweden

3 Centre for Epidemiology and Community Medicine, Stockholm, Sweden

4 Research Group Epidemiology of Psychiatric Conditions, Substance Use and Social Environment (EPICSS), Department of Public Health Sciences, Karolinska Institutet, Solnavägen 1E, SE-171 77 Stockholm, Sweden

\section{Background}

Over recent decades, international migration has reached unprecedented levels [1]. The number of international migrants-defined by the International Organisation for Migration as individuals living outside their country of birth—reached an estimated 272 million in 2019 [2]. While globalisation has made migration easier and cheaper, a host of other factors including conflict, poverty, and adverse effects of climate change have contributed to increasing numbers of people forced to leave their homes.

The upward trend in migration has coincided with growing recognition of migration as a social determinant of health [3, 4]. The combination of socioeconomic, environmental, and political factors that migrants are exposed 
to pre-, during, and post-migration interact to impact their health [5]. Given the heterogeneity of circumstances under which migration occurs [2], the range of health risks and protective factors that migrants are exposed to is broad [5].

Although generalisations about migrants should be made with caution, migrants face cultural, legal, and socioeconomic barriers to accessing healthcare in their host countries $[6,7]$. Commonly reported barriers include communication difficulties, cultural differences leading to dissatisfaction with services, discrimination, and issues obtaining care without permanent status [8].

Care-seeking behaviour has been defined as "a problemfocused, planned behaviour, involving interpersonal interaction with a selected healthcare professional" [9]. This definition does not include care-seeking from informal sources, such as traditional healers or social networks, which are also important forms of care-seeking within many communities [10]. Several studies have demonstrated that migrant groups in high-income countries (HICs) exhibit generally lower care-seeking behaviour from health professionals than the wider population [11-14]. The reasons behind this are not well understood, but are likely linked to the barriers to care $[6,7]$ and even care-seeking from informal sources [10].

Various health conditions, such as sexually transmitted infections (STIs) including HIV [15], and mental health problems such as depression [16], are associated with stigma. Stigma is defined by the Cambridge Dictionary as "a strong feeling of disapproval that most people in society have about something", and these stigmatised conditions are often associated with barriers to care in general populations $[16,17]$. As migrant populations are often themselves stigmatised within society [18], they likely face further barriers to seeking care for stigmatised conditions than the rest of the population. One qualitative study with sub-Saharan African immigrants in Australia, for example, identified fear of rejection within the community as a barrier to seeking mental health care [19]. Indeed, care-seeking for stigmatised conditions is low amongst migrant groups [7].

The availability of effective treatments for many stigmatised conditions has increased [15, 20], particularly in high-income countries. However, barriers to care and subsequent low care-seeking prevent migrant populations from accessing these vital services. Delaying or not seeking care has been associated with poorer health outcomes [21] and can widen health disparities between vulnerable groups and the wider population [7]. Improving migrants' care-seeking behaviour for stigmatised conditions in high-income countries could, therefore, has a significant impact on migrant health.

Interventions implemented to improve migrant health and care-seeking have been previously documented [22]. Prior to this review, however, the scope of the evidence on interventions implemented to increase migrants' care-seeking for stigmatised conditions in high-income countries was unknown. A scoping review approach was therefore deemed appropriate for this study [23]. The objectives were to assess the scope of the literature and to gather knowledge on intervention features and outcomes. The overarching purpose was to inform the design of an intervention to increase migrants' care-seeking behaviour for children and young peoples' mental health services in Stockholm, Sweden.

\section{Scoping review question}

Which interventions to increase migrants' care-seeking behaviour for stigmatised conditions have been implemented in high-income countries?

\section{Methodology}

\section{Protocol and registration}

Two reviewers (VP \& BN) developed the review protocol using PRISMA-ScR guidance on conducting scoping reviews [23], based upon Arksey and O'Malley's methodological framework and later guidance [24, 25]. The protocol was modified following literature searches and feedback from the research team. The final version, and the PRISMAScR checklist, are included as appendices (Appendix 1 and 2).

\section{Eligibility criteria}

Studies that met the following criteria were considered: study design included an intervention that was implemented in a high-income country (using the World Bank's Classification of Countries by Income [26], from the year that each study was conducted); the intervention was designed to increase initial care-seeking behaviour from a healthcare professional for a stigmatised condition; the main study population was international migrants, and/or their children. Studies that compared outcomes between migrant groups and the wider population were included. Studies that targeted a vulnerable subgroup (such as homeless migrants) were excluded, as preliminary literature searches indicated that these studies focussed on lowering barriers associated with subgroup, not migrant, status. Studies conducted in low- or middle-income countries were beyond the scope of this review and were excluded.

The focus of this scoping review was the initial care-seeking act (the first time an individual seeks professional help for a health problem), thus interventions that sought to retain patients in care were not included. Interventions to improve adherence to a treatment regimen, or to promote screening or vaccination, were excluded. Interventions that sought to 
improve attitudes towards care-seeking, or willingness to seek care, were included.

Moreover, the purpose of this study was to inform the design of an intervention to increase care-seeking for mental health problems amongst migrant populations. Prior to conducting this scoping review, the number of studies reporting interventions to improve care-seeking for mental health problems was anticipated to be low, thus interventions to improve care-seeking for any stigmatised condition were included. All years, study designs, and publication types were considered for inclusion, including peer-reviewed and grey literature.

\section{Information sources and search strategy}

The authors collaborated with information experts at Karolinska Institutet University Library to develop a comprehensive search strategy that was continually revised. Searches of 13 electronic databases and websites, covering peerreviewed and grey literature (PubMed; Web of Science; PsycINFO; Global Health; Google Scholar; Mednar; ProQuest; DART-Europe; OAIster; Bielefeld Academic Search Engine (BASE); National Center for Biotechnology Information (NCBI) Bookshelf; the World Health Organisation; Norwegian Institute of Public Health), as well as hand-searches of key journals within the field (Ethnicity \& Health; BMC Public Health, selected by VP and $\mathrm{ACH}$ ), were conducted from 10/06/2019 until 05/07/2019. The search strategy for PubMed is presented Supplementary Fig. 1; other search strategies are available upon request. The search was limited to studies published in English or Swedish. Manual searches of citations on Google Scholar (citation tracking) and references lists (reference scans) were conducted to identify additional studies for review.

\section{Selection of sources of evidence}

Study selection was an iterative process, and the search strategy was modified following new findings in the literature. Search results were imported into Mendeley reference management software and screened against the eligibility criteria. Titles and abstracts were screened independently by VP and BN, who met to decide which studies were eligible for full-text screening. Full-text screens of these studies were conducted independently by VP and BN, who then decided the final list of studies for inclusion. Disagreements were resolved by consultation with the research team.

\section{Data items and the data charting process}

The following data were extracted from studies: (i) author(s), publication year, location; (ii) study population (e.g. ethnic group); (iii) study design; (iv) intervention characteristics (e.g. language); (v) stigmatised condition(s); and (vi) reported outcomes related to the scoping review question (e.g. psychiatric service utilisation), using a custom-built data extraction form.

The data extraction form was developed by VP and independently piloted on three included studies by VP and BN. The reviewers then discussed the form with the research team, using feedback to adjust as necessary. As far as possible, reviewers sought to extract data as reported in the studies. Methodological details that were not explicitly stated, such as sampling method, were inferred from the manuscript.

\section{Synthesis of results}

Descriptive data from included studies were summarised in text and table format (Table 1). To synthesise results on the type of interventions reported in included studies, qualitative synthesis using qualitative content analysis [27] was employed. Reported interventions were organised thematically, into themes corresponding to the approach taken to increase care-seeking behaviour by $\mathrm{VP}, \mathrm{BN}$ and $\mathrm{ACH}$. This was an iterative process, using the intervention type as the primary unit of analysis and involving discussion with the research group to address potential biases and preconceptions of the reviewers.

Several subthemes, representing approaches taken to increase care-seeking, emerged from the overarching themes. Interventions within each theme were further categorised, where appropriate, into these subthemes. Themes and subthemes were discussed between the researchers until a consensus was reached.

\section{Critical appraisal}

Consistent with PRISMA-ScR guidance on conducting scoping reviews [23], the methodological quality and risk of bias of the included studies were not assessed.

\section{Results}

\section{Selection of sources of evidence}

The literature search and screening process are shown in Fig. 1. Sixteen studies were selected for inclusion, presented in Table 1.

\section{Characteristics of sources of evidence}

All studies were conducted in North America; 15 in the USA and one in Canada. One study sought to increase care-seeking behaviour for Hepatitis B Virus (HBV) infection [28] 


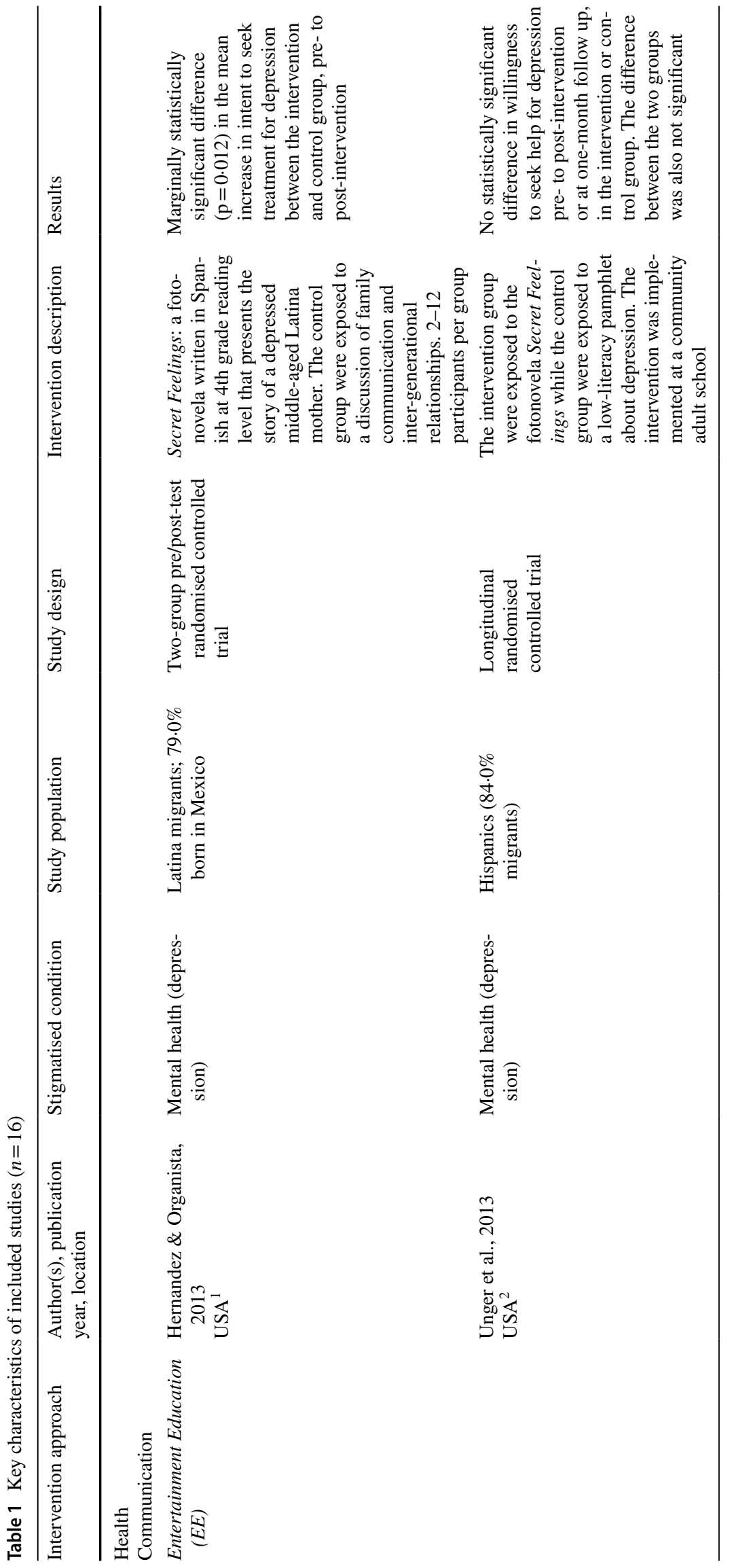




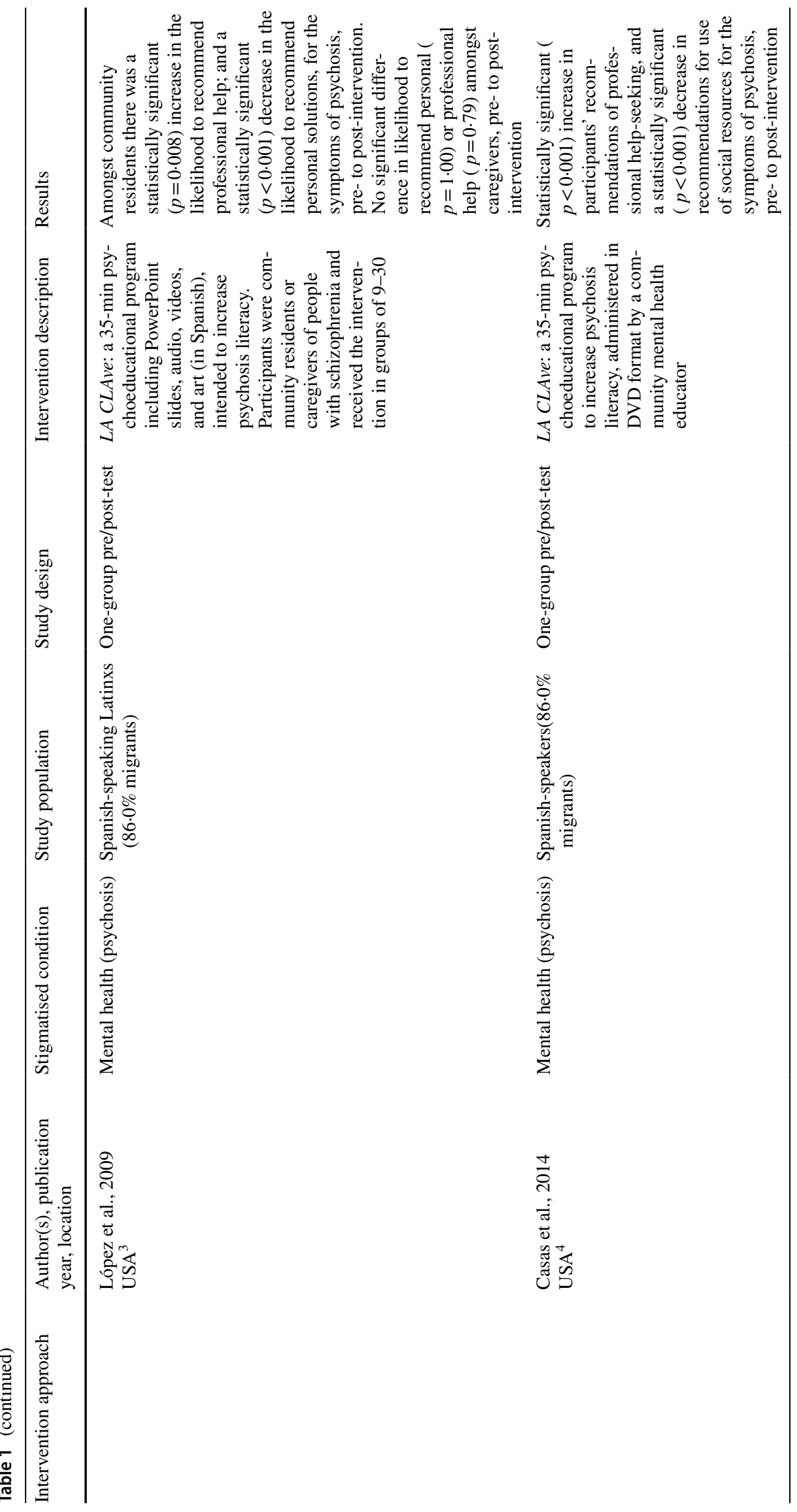




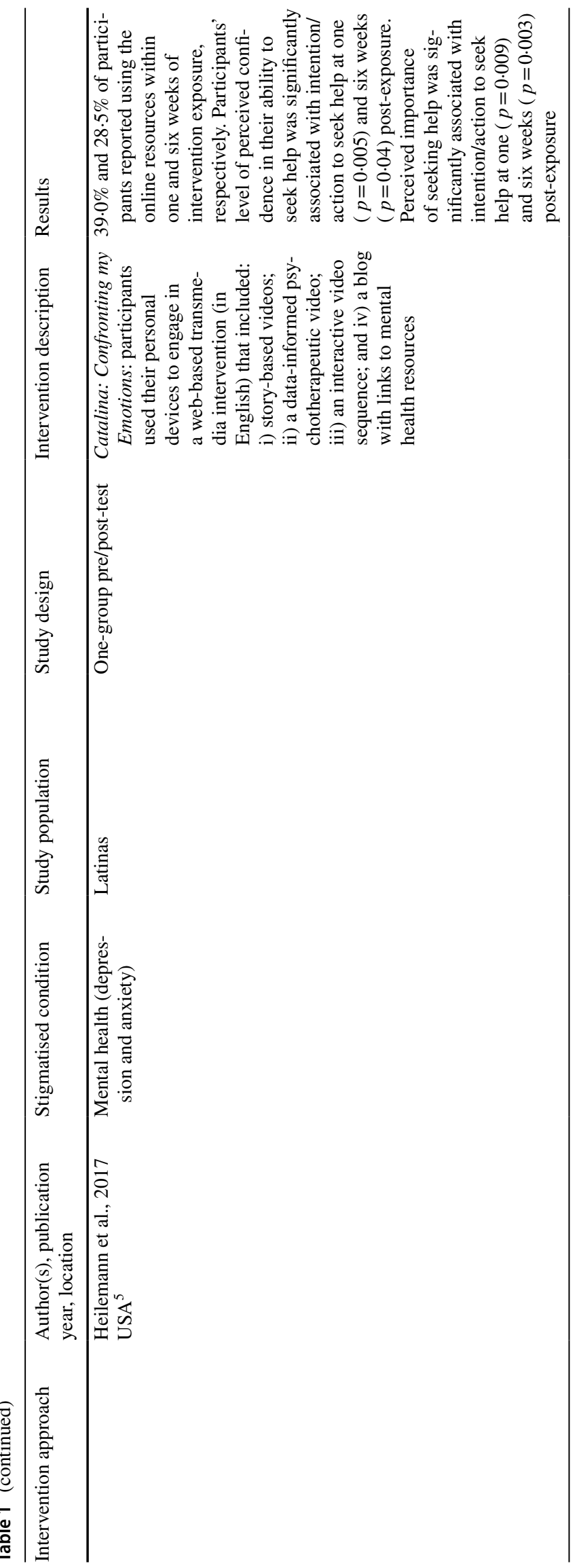




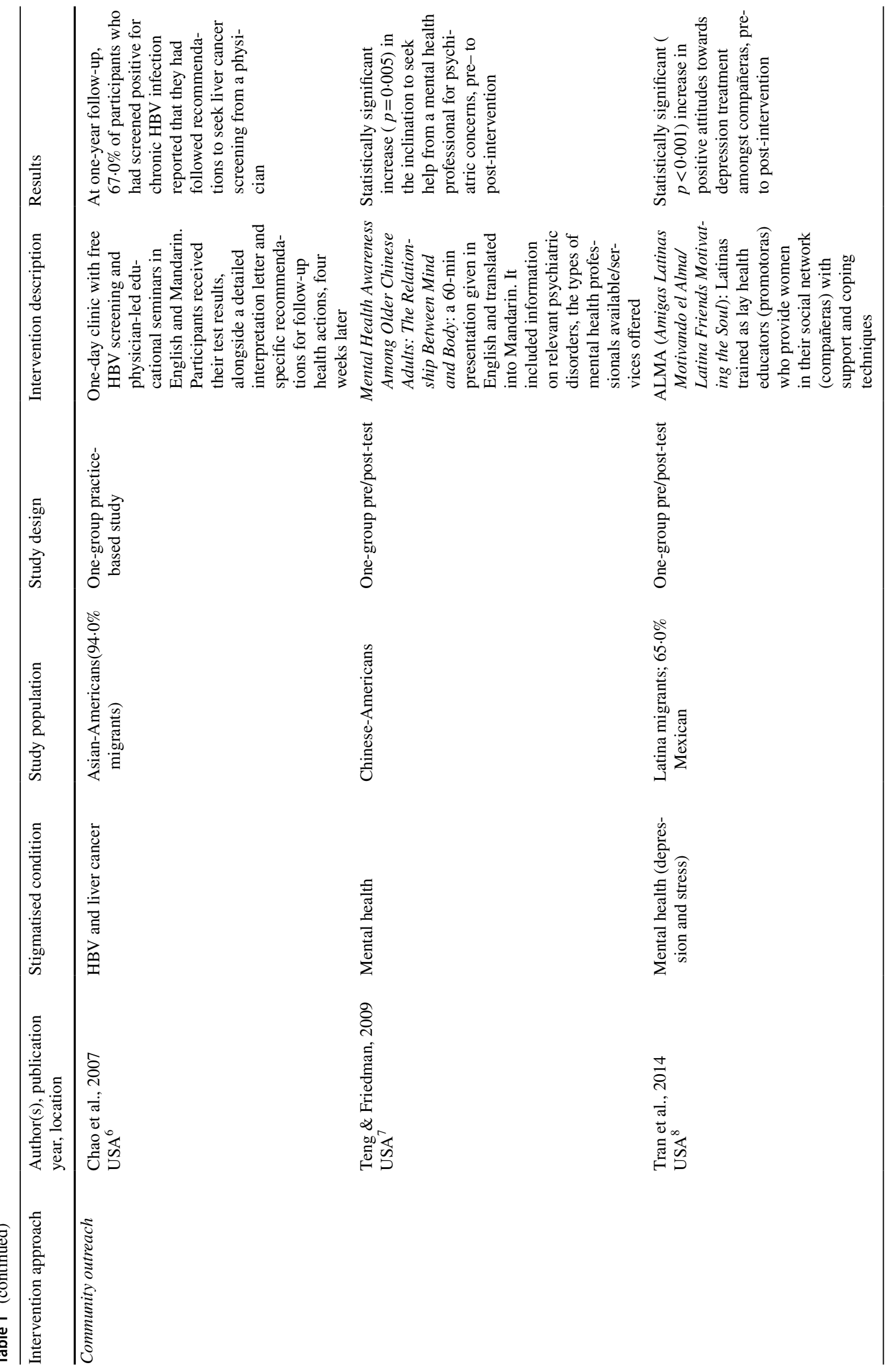




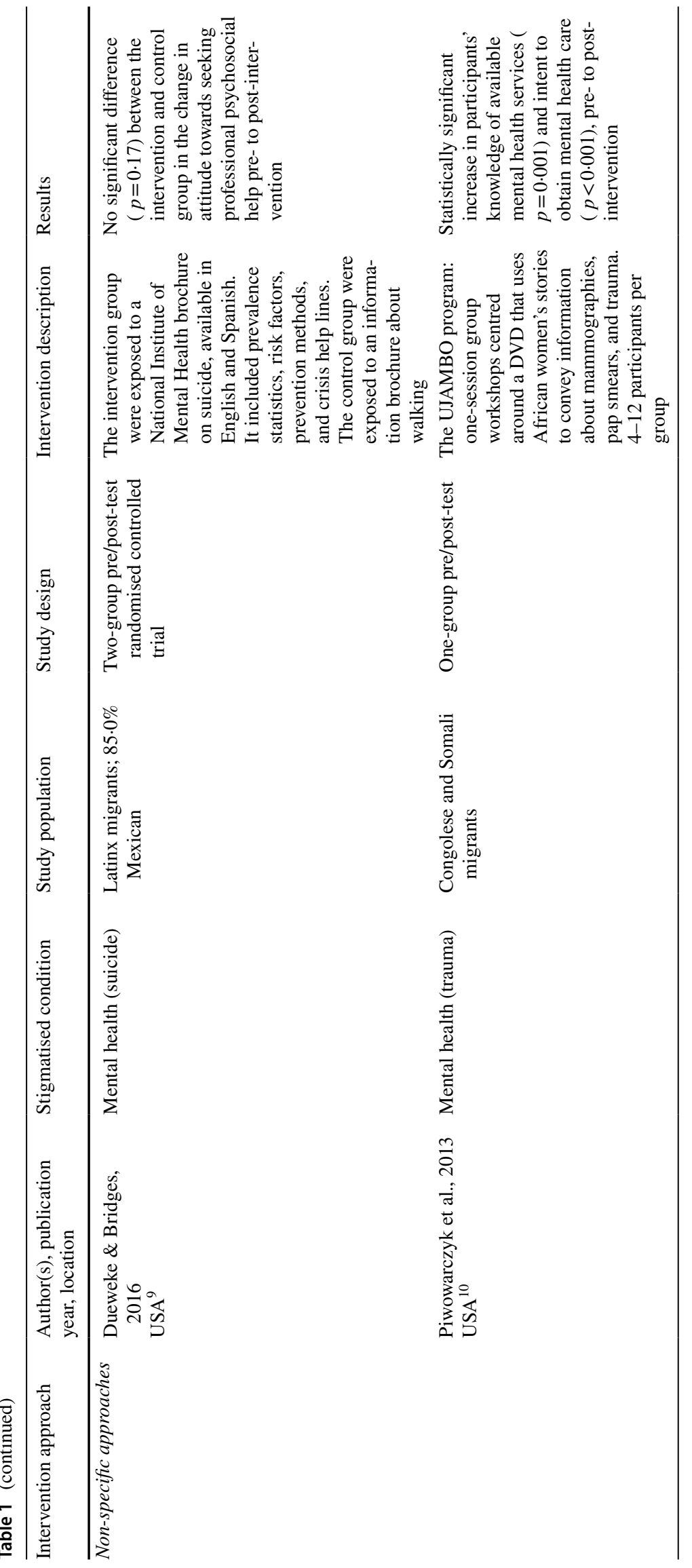

黛 Springer 


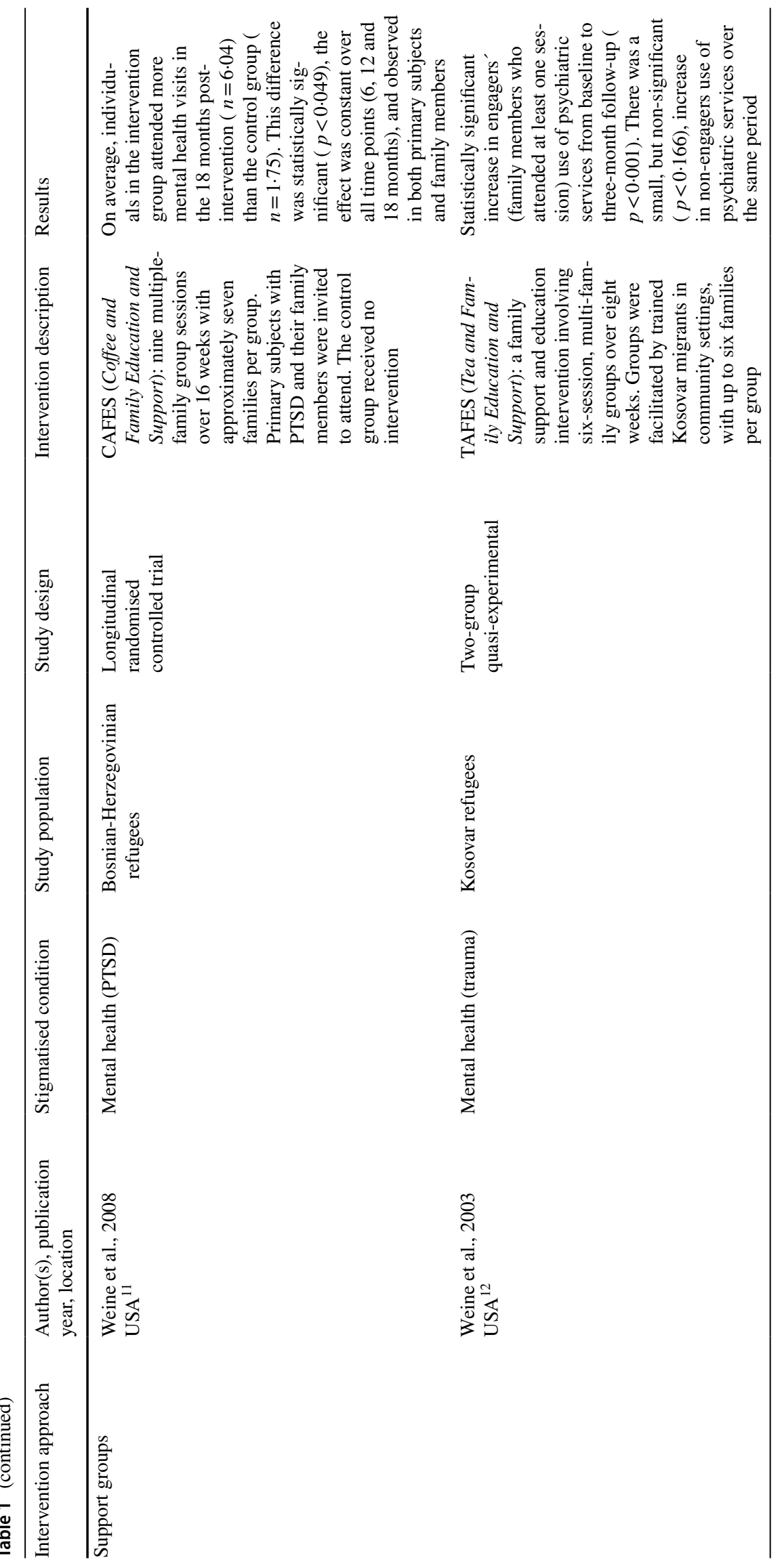




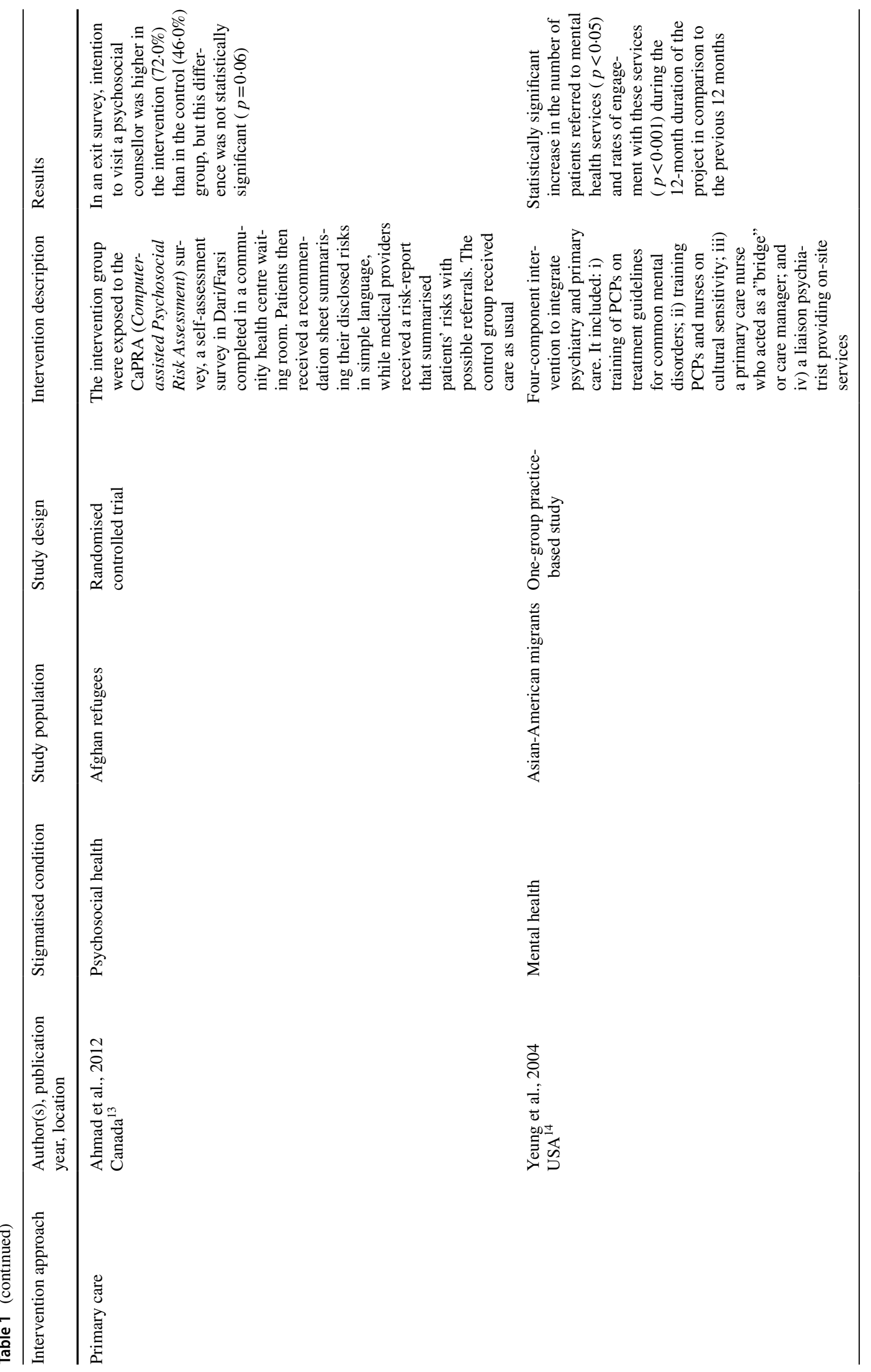




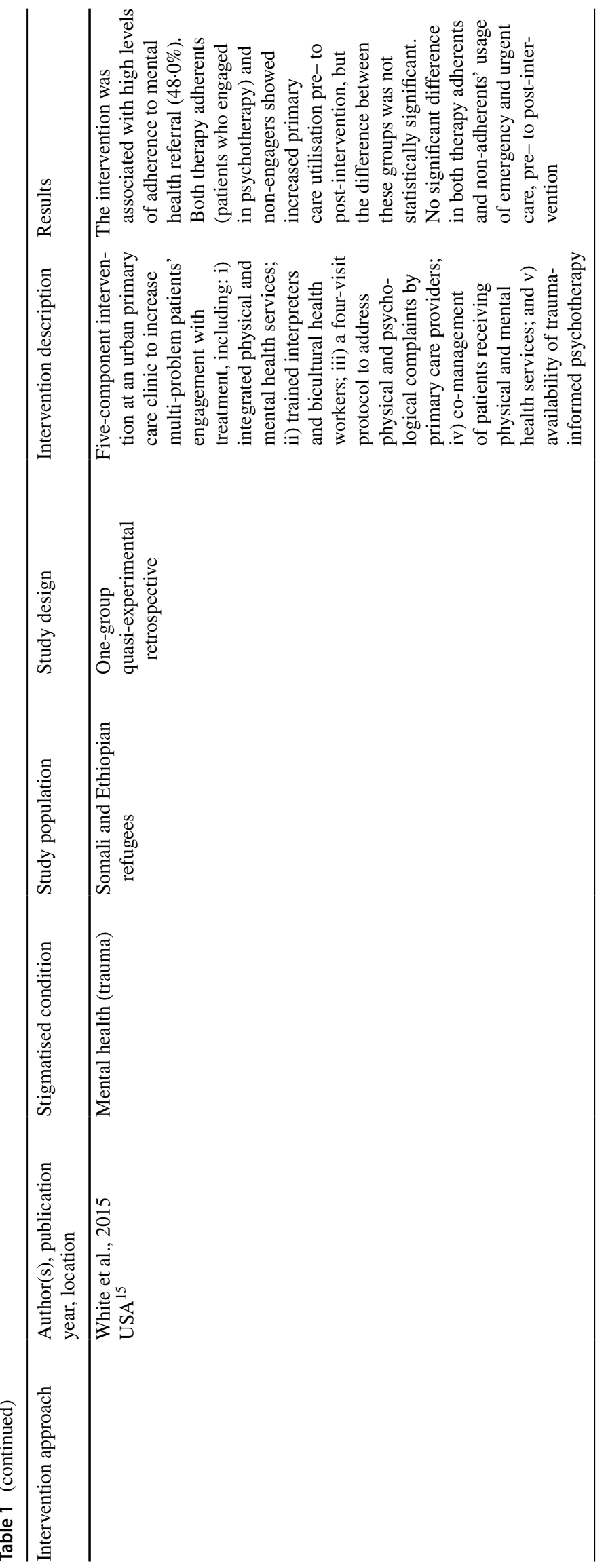




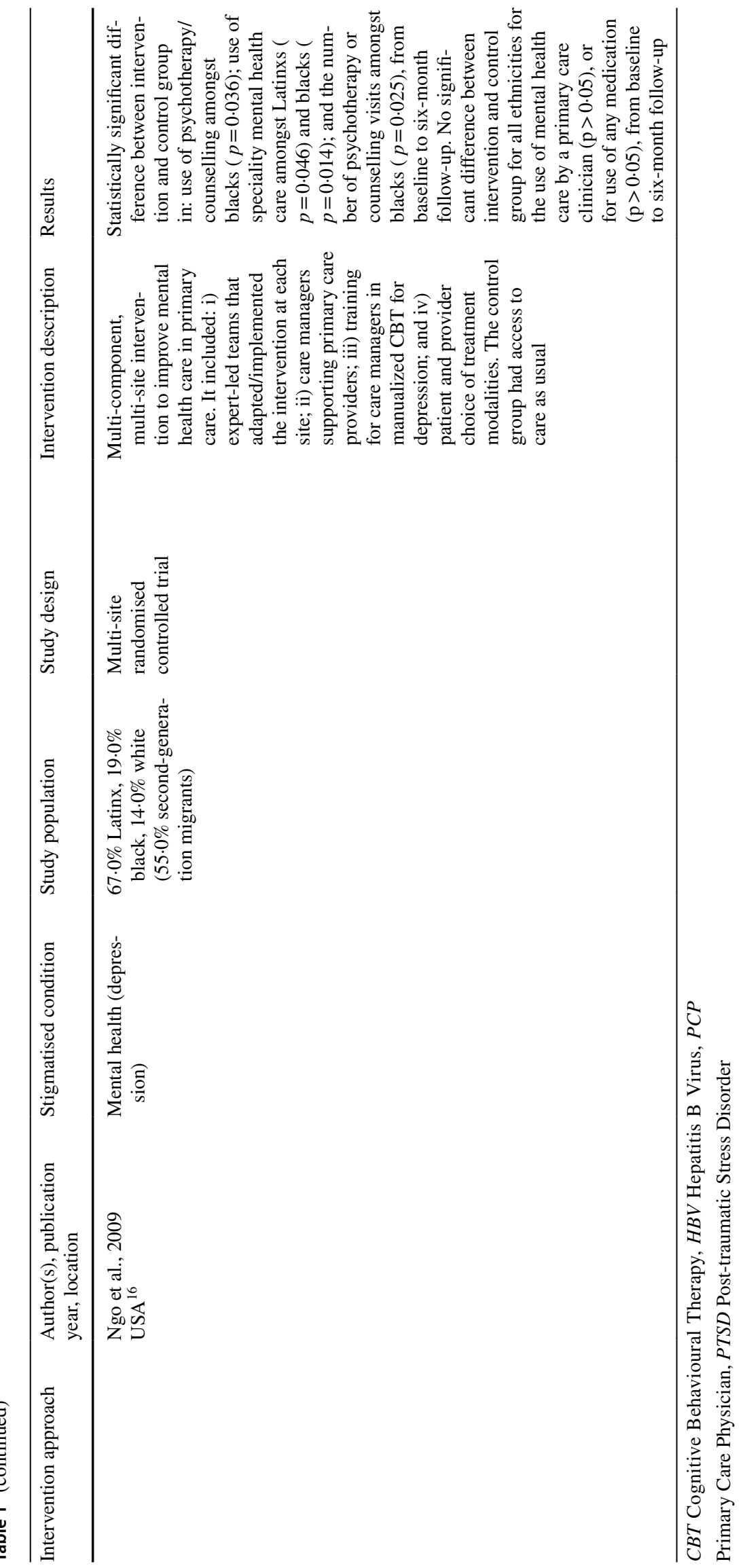


Fig. 1 Study selection

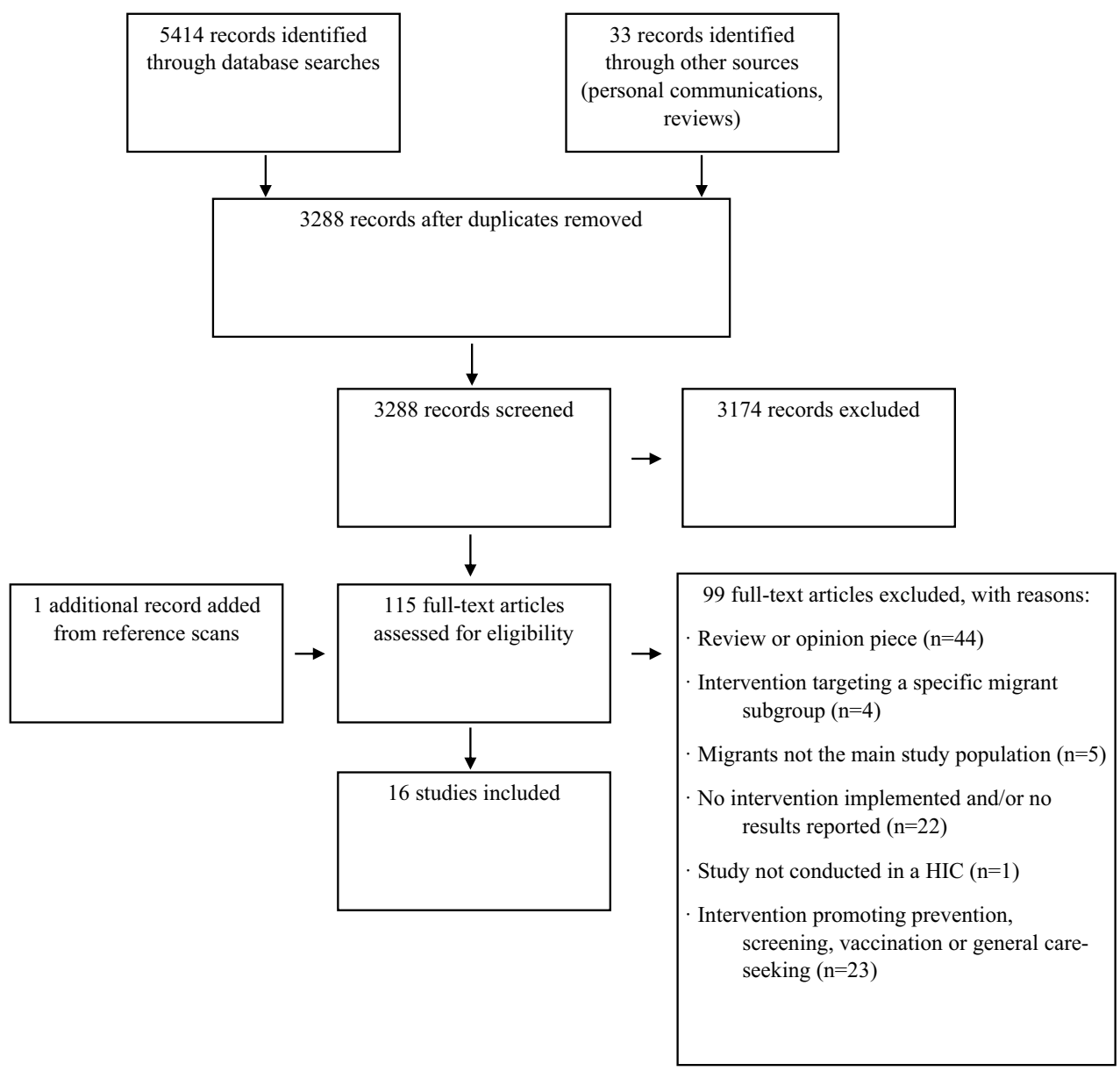

HIC $=$ High-income country.

and 15 studies for mental health problems (Table 1) [29-43]. Ten studies measured care-seeking behaviour via participants' intent or willingness to, or their attitudes towards, care-seeking [29, 30, 35-37, 40, 43]. Six studies used care utilisation to measure care-seeking behaviour [28, 32-34, 39]. In 14 studies, outcome measures were self-reported, via surveys or interviews, while in two studies, data were extracted from clinical records (Suppl. Table 2) [33, 34].

Study population characteristics are presented in Supplementary Table 1. All studies besides three [28, 31, 43], included mainly or all female participants. One study [39] included participants aged below 17 years; the rest included participants aged 17 and over. A range of migrant groups participated in the interventions (Suppl. Table 1), and all interventions but one [39] were tailored towards an ethnic group or region of origin. The most common group was Latinxs-individuals of Latin American cultural or racial descent-or Hispanics ( $n=7$ ) (Suppl. Table 1) [30, 35-38, $42,43]$. Detailed information on study design and intervention characteristics is presented in Supplementary Table 2 and 3 , respectively.

\section{Results of individual sources of evidence and synthesis}

Three themes emerged during qualitative content analysis [26], corresponding to the approaches utilised to increase care-seeking: (i) health communication; (ii) support groups; and (iii) primary care-based approaches. Detailed information on the findings of the studies is presented in Table 1.

\section{Health communication}

Health communication (the strategies used to inform, influence, and motivate audiences about health issues) [44] to increase care-seeking behaviour was tested in ten studies [28, 30, 35-38, 40-43], via three different approaches: entertainment education (EE), community outreach, and nonspecific approaches. Entertainment education (EE) refers to the placement of educational content within entertainment [45]; an approach employed by five studies. Two studies $[37,43]$ tested the effectiveness of a fotonovela, a booklet portraying a dramatic story through pictures and captions, 
as a tool to increase health literacy and care-seeking for depression amongst Latinx populations. Both studies tested the fotonovela Secret Feelings. The intervention groups in these studies showed a marginally statistically significant, or no statistically significant, difference in the intention or willingness to seek help for depression compared to controls $[37,43]$.

Two studies tested the effectiveness of a psychoeducational program to increase health literacy and help-seeking for psychosis amongst Latinxs $[30,38]$. Both studies reported an improvement in the likelihood that participants would recommend professional help-seeking for the symptoms of psychosis, but this was not observed in all groups (Table 1) [30,38]. One study tested the effectiveness of a web-based transmedia intervention; over six weeks, Latinas (Latinx women) with symptoms of depression and anxiety accessed media designed to reduce reluctance to seek help for these conditions [36]. The study found that participants' perceived confidence in their ability to, and in the importance of, seeking help were both positively associated with intention or action to seek help, post-intervention [36].

Three studies [28, 41, 42] used community outreach approaches to communicate health information and increase care-seeking. In one study, Latinas were trained as community health educators (promotoras) who contacted women in their community (compañeras) and provided them with information and coping skills for depression [42]. This study reported a statistically significant increase in positive attitudes towards depression treatment amongst compañeras, pre- to post-intervention [42].

Teng and colleagues implemented educational seminars about mental health for Chinese-American elders, in English and Mandarin, at a community church, and participants showed an increased inclination to seek help for psychiatric concerns following the intervention [41]. Similarly, Chao and colleagues implemented a one-day screening and informational clinic on HBV, as part of an educational outreach campaign in the Asian-American community [28]. The clinic offered free screening and physician-led educational seminars in English and Mandarin. An year later, one-third of the participants who had screened positive for chronic HBV infection reported that they had followed recommendations to seek liver cancer screening [28].

Two studies took non-specific health communication approaches to increasing care-seeking [35, 40]. One study tested the effectiveness of a brochure to increase careseeking for suicidal thoughts amongst Latinxs, but no significant difference was observed between intervention and control groups in the change in attitude towards professional help-seeking [35]. Piwowarczyk and colleagues sought to increase care-seeking for trauma amongst East African women via a DVD-centered workshop, using African immigrant women's stories to portray basic health information
[40]. Pre- to post-intervention, there was a statistically significant increase in participants' knowledge of, and intent to obtain, mental health care [40].

\section{Support groups}

Weine and colleagues utilised support groups as a tool to increase care-seeking for trauma amongst Kosovar refugees [32] and PTSD amongst Bosnian-Herzegovinians [31], in two separate studies. Both interventions were based on family coping and support techniques, using multi-family group sessions to facilitate adjustment $[31,32]$. Both studies reported statistically significant increases in the use of psychiatric or mental health services amongst participants who attended the support groups, compared to controls [31, 32].

\section{Primary care-based approaches}

Four interventions took primary care-based approaches to increase migrants' care-seeking for stigmatised conditions (Table 1) [29, 33, 34, 39]. One study piloted a self-assessment tool for psychosocial risk with Afghan refugees [29]. Three studies sought to increase migrants' engagement with mental health services via multi-component primary carebased interventions, which sought to increase collaboration between the two services (Table 1) [33, 34, 39]. All three multi-component approaches reported some improvement in various measures of care-seeking and engagement with services following the interventions $[33,34,39]$. The selfassessment tool reported higher intention to visit a psychosocial counsellor in the intervention group compared to controls, but this was not statistically significant (Table 1) [29].

\section{Results in context}

This scoping review mapped the evidence for interventions implemented to increase migrants' care-seeking behaviour in high-income countries for stigmatised conditions. The relatively few included studies $(n=16)$, all from North America, indicates limited evidence within this field, while the features of reported interventions reveal several key trends. Interventions were typically tailored to one migrant group in terms of language, content, and delivery, reflecting the notion that no "one size fits all". All interventions were community-based, indicating a trend towards local interventions. Ten interventions were administered in groups [28, 30-32, $35,37,38,40,41,43]$, which can reduce costs, but fear of stigma could hinder attendance. Latinxs, Hispanics, and Asian-Americans were the most represented migrant groups in included studies (Table 1). This could indicate high burden of disease amongst these groups; it could also reflect the 
North American setting, or higher advocacy amongst these migrant communities than others.

Thirteen studies [28, 30-34, 36-42] reported improvements in participants' care-seeking, while three [29, 35, 43] reported no effect (Table 1). Interventions that improved care-seeking were typically more complex and resourceintensive, which will be unpacked further in coming paragraphs. Given the stigmatisation of migrant populations [18] and the complexity of care-seeking for stigmatised conditions, these findings suggest that simple interventions may not suffice to improve this-an important finding for policymakers and researchers.

Health communication was the most commonly used approach to increase migrants' care-seeking [28, 30, 35-38, 40-43]; and interventions within its three subthemes (Table 1) shared common features. Information and delivery mode were tailored to the cultural preferences and literacy of target populations. A fotonovela was, for example, written at 4 th-grade reading level to accommodate low literacy, and showed marginally positive effects on intent to seek care $[37,43]$. Interestingly, a brochure on suicide that was not adapted to its target population's literacy level (Table 1) [35] did not improve care-seeking. Adapting interventions to participants' literacy level may be important to increase care-seeking, but the evidence is not conclusive.

There is a growing interest in health communication to improve health literacy and care-seeking behaviour. Low-health literacy has been documented as a barrier to migrants' care-seeking for HIV [15] and mental health [46], thus health communication may be a promising approach to increase care-seeking for stigmatised conditions. However, designing and implementing health communication interventions (often specific to one group) can be resource intensive, requiring in-depth knowledge of target populations. In addition, the varied findings of the health communication studies reported here (Table 1) do not conclusively support the effectiveness of this type of intervention. Further research into which types of health communication are effective, for whom, and in what context, is required.

The support group interventions also sought to increase care-seeking via improving health literacy [31, 32]. Moreover, these interventions utilised a holistic approach to facilitate care-seeking, building a support network within and between families over several months. The reliability of the RCT design and extended follow-up of participants suggests that these were more resource-intensive than some of the simple health communication interventions [30, 37, 38, 41] and their conclusions more reliable. Indeed, the reported improvements to care-seeking amongst participants over a sustained period post-intervention (Table 1) suggest that further research into the efficacy of support groups in other contexts is warranted.
Primary care-based focussed on removing structural, as opposed to personal, barriers to care. The interventions within this group that successfully improved care-seeking [32, 33, 39] were multi-component; targeting several aspects of primary care (Table 1) to improve access to mental health care. The findings suggest that using primary care settings as a gateway to stigmatised condition care could be a promising avenue for further research.

This review identified several gaps in the literature. Of the 5447 hits retrieved in the literature search (Fig. 1), only 16 were selected for inclusion, all from the USA and Canada. The low number of eligible studies is surprising, so it is possible that exclusion criteria led to a selection bias. However, given the comprehensiveness of the search strategy, it is unlikely that many studies were missed. The low number of included studies likely reflects a lack of research and reporting within this field.

Given the marked increase in migration to Europe and interest in migrant health [47], the absence of European studies was surprising. Moreover, studies including minors [39] and men were underrepresented or absent, respectively. Migration is a risk factor for various mental health problems in minors [48], for example, yet research suggests that they exhibit lower care-seeking behaviour than hosting populations [49]. The lack of interventions targeting men and minors may reflect lower priority given to men, or the perceived challenges of engaging these already stigmatised groups for stigmatised conditions.

Fifteen included studies [29-43] sought to improve careseeking for mental health problems, reflecting the rapid expansion of the migrant mental health field over recent decades [3]. Interventions that targeted other stigmatised conditions with high prevalence amongst some migrant groups, such as HIV and TB, were noticeably missing. One possible explanation is that care-seeking research for these conditions is more focussed on vaccination or treatment adherence, which were not included in this review.

Another important finding is that study design was often a limitation of included studies; half of included studies [29, $30,36-38,40-42]$ measured outcomes immediately postintervention, which does not allow the long-term strength of effects to be measured. Six studies [30, 36, 38, 40-42] employed a one group pre/post-test design, preventing comparison with controls. Moreover, intent or attitudes towards seeking care [29, 30, 35-38, 40-43] do not necessarily translate to care utilisation, particularly for stigmatised conditions where desirability bias may be high. Fourteen studies [28-32, 35-43] used self-reported outcome measures, which further introduce desirability and recall bias. The bias introduced through study design prevents us from drawing reliable conclusions on the effectiveness of included interventions, a limitation of this review. It is also important to consider the role of the stigmatisation of migrant groups 
themselves, aside from the stigmatisation of the conditions, which was not explored in included studies and would likely influence findings.

This scoping review has several other limitations. Publication bias towards positive results is a common issue in intervention research. Although null findings were reported $[29,33,35,38,39,43]$, several of these were associated with improvements in variables besides care-seeking. Interventions that did not achieve any positive results may not been reported in the literature and thus were missed. Therefore, although not as strong as anticipated, publication bias is still a limitation of this review.

The definition of care-seeking utilised [9] does not included seeking support from informal sources, as the purpose of the review was to inform an intervention to increase care-seeking from mental health professionals. However, research has shown that these are important sources of support for many migrant communities [10], which could impact care-seeking from healthcare professionals. Further research into the relationship between these forms of care-seeking in migrant communities are needed. Similarly, improving our understanding of factors that influence low care-seeking amongst migrant populations will be critical to designing effective interventions to address this issue.

The literature search was limited to English and Swedish language articles, in the 15 included databases and key journals, thus relevant articles published in other databases and languages are likely missing. Furthermore, the review's scope was limited by the review question and purpose. Our focus was initial care-seeking, for example, so we are unable to comment on retention of migrants in care. Further scoping reviews are needed to map the evidence in these areas. A critical appraisal of included studies was not conducted, and the heterogeneity of measured outcomes meant that it was not possible to conduct a meta-analysis, limiting comparisons between studies and interpretation of their findings.

\section{Conclusion}

Care-seeking behaviour is a complex issue, so it is unsurprising that no "silver bullet" approach to improve care for conditions associated with stigma among migrants in high-income countries was found. Our findings do, however, reveal various trends in the field. Interventions were typically tailored to one migrant group and these were often either community- or group-based. This knowledge was used to inform the design of a multi-arm, community-based intervention, with health communication components, to improve care-seeking for mental health problems amongst migrant populations in Stockholm, Sweden. Significant gaps in the literature remain, and the included study designs were limited to discern intervention effectiveness. We recommend that future studies seek to fill these knowledge gaps, using more reliable study designs, to better inform effective policy on migrant health.

Supplementary Information The online version contains supplementary material available at https://doi.org/10.1007/s00127-021-02065-1.

Acknowledgements Not applicable

Author contributions $\mathrm{CD}$ and $\mathrm{ACH}$ conceived the project. VP and $\mathrm{BN}$ carried out the database searches, screened titles, abstracts, and full texts, extracted data from citations, and carried out data analysis. VP wrote the manuscript with contributors $\mathrm{ACH}, \mathrm{BN}, \mathrm{KA}$ and SB. All authors reviewed the study findings and read and approved the final version before submission. $\mathrm{ACH}$ provided supervision to $\mathrm{VP}$ and $\mathrm{BN}$, and critically revised the manuscript at all stages.

Funding Open access funding provided by Karolinska Institute. Swedish research council (Vetenskapsrådet) grant nr: 2018-05763. Hollander/Forte 2016-00,870/Psykiatrisk vård bland utrikesfödda.

Availability of data and materials All data generated or analysed during this study are included in this published article and its supplementary information files.

\section{Declarations}

Conflict of interest The authors declare that they have no conflict of interest.

Ethics approval and consent to participate Not applicable.

Consent for publication Not applicable.

Open Access This article is licensed under a Creative Commons Attribution 4.0 International License, which permits use, sharing, adaptation, distribution and reproduction in any medium or format, as long as you give appropriate credit to the original author(s) and the source, provide a link to the Creative Commons licence, and indicate if changes were made. The images or other third party material in this article are included in the article's Creative Commons licence, unless indicated otherwise in a credit line to the material. If material is not included in the article's Creative Commons licence and your intended use is not permitted by statutory regulation or exceeds the permitted use, you will need to obtain permission directly from the copyright holder. To view a copy of this licence, visit http://creativecommons.org/licenses/by/4.0/.

\section{References}

1. United Nations. International Migration Report (2017) Highlights [Internet]. UN; 2018. 1-38 p. (Statistical Papers - United Nations (Ser. A), Population and Vital Statistics Report). https://www.unilibrary.org/international-law-and-justice/international-migrationreport-2017-highlights_5e2626a2-en\%0A. https://www.un.org/en/ development/desa/population/migration/publications/migrationr eport/docs/MigrationReport2017_Highlights.pdf

2. IOM, WHO, UN. International Migration, Health and Human rights. International Migration, Health and Human rights. 2013.

3. Sweileh WM, Wickramage K, Pottie K, Hui C, Roberts B, Sawalha AF et al (2018) Bibliometric analysis of global migration 
health research in peer-reviewed literature (2000-2016). BMC Public Health 18(1):1-18

4. Abubakar I, Aldridge RW, Devakumar D, Orcutt M, Burns R, Barreto ML, et al. The UCL-Lancet Commission on Migration and Health: the health of a world on the move. Lancet [Internet]. 2018 Dec 15;392(10164):2606-54. https://doi.org/https://doi.org/ 10.1016/S0140-6736(18)32114-7

5. Hossin MZ (2020) International migration and health: it is time to go beyond conventional theoretical frameworks. BMJ Glob Heal 5(2):e001938

6. Patel K, Kouvonen A, Close C, Väänänen A, O'Reilly D, Donnelly M (2017) What do register-based studies tell us about migrant mental health? A scoping review. Syst Rev 6(1):1-11

7. Woodward A, Howard N, Wolffers I (2014) Health and access to care for undocumented migrants living in the European Union: a scoping review. Health Policy Plan 29(7):818-830

8. Hiam L, Gionakis N, Holmes SM, McKee M (2019) Overcoming the barriers migrants face in accessing health care. Public Health [Internet]. 172:89-92

9. Cornally N, Mccarthy G (2011) Help-seeking behaviour: A concept analysis. Int J Nurs Pract 17(3):280-288

10. Hernández-Plaza S, Alonso-Morillejo E, Pozo-Muñoz C (2006) Social support interventions in migrant populations. Br J Soc Work 36:1151-1169. https://doi.org/10.1093/bjsw/bch396

11. Klein J, von dem Knesebeck O. Inequalities in health care utilization among migrants and non-migrants in Germany: a systematic review. Int J Equity Health 2018. doi:https://doi.org/10.1186/ s12939-018-0876-z

12. Gerritsen AAM, Bramsen I, Devillé W et al (2006) Use of health care services by Afghan, Iranian, and Somali refugees and asylum seekers living in the Netherlands. Eur J Public Health 16:394-399. https://doi.org/10.1093/eurpub/ck1046

13. Manhica H, Almquist Y, Rostila M et al (2017) The use of psychiatric services by young adults who came to Sweden as teenage refugees: a national cohort study. Epidemiol Psychiatr Sci 26:526-534. https://doi.org/10.1017/S2045796016000445

14. Satinsky E, Fuhr DC, Woodward A et al (2019) Mental health care utilisation and access among refugees and asylum seekers in Europe: a systematic review. Health Policy (New York) 123:851863. https://doi.org/10.1016/j.healthpol.2019.02.007

15. Levison JH, Levinson JK, Alegría M (2018) A critical review and commentary on the challenges in engaging HIV-infected latinos in the continuum of HIV Care, vol 22. New York LLC, AIDS and Behavior. Springer, pp 2500-2512

16. Schnyder N, Panczak R, Groth N, Schultze-Lutter F (2017) Association between mental health-related stigma and active helpseeking: Systematic review and meta-analysis. Br J Psychiatry 210(4):261-268

17. Craig GM, Daftary A, Engel N, O’Driscoll S, Ioannaki A (2017) Tuberculosis stigma as a social determinant of health: a systematic mapping review of research in low incidence countries. Int J Infect Dis 56:90-100

18. Morey BN (2018) Mechanisms by which anti-immigrant stigma exacerbates racial/ethnic health disparities. Am J Public Health 108:460-463. https://doi.org/10.2105/AJPH.2017.304266

19. McCann TV, Renzaho A, Mugavin J, Lubman DI (2018) Stigma of mental illness and substance misuse in sub-Saharan African migrants: a qualitative study. Int J Ment Health Nurs 27(3):956-965

20. Collin S, Wurie F, Muzyamba M, Vries G, Lönnroth K, Migliori GB et al (2019) Effectiveness of interventions for reducing TB incidence in countries with low TB incidence: a systematic review of reviews. Eur Respir Rev 30(28):180107

21. Sarmiento K, Hirsch-Moverman Y, Colson PW, El-Sadr W (2006) Help-seeking behavior of marginalized groups: a study of TB patients in Harlem, New York. Int J Tuberc Lung Dis 10(10):1140-1145

22. Diaz E, Ortiz-Barreda G, Ben-Shlomo Y, Holdsworth M, Salami B, Rammohan A et al (2017) Interventions to improve immigrant health. A scoping review. Vol. 27. Eur J Publ Health 2017:433-9

23. Tricco AC, Lillie E, Zarin W, O'Brien KK, Colquhoun H, Levac $D$ et al (2018) PRISMA extension for scoping reviews (PRISMAScR): checklist and explanation. Ann Intern Med 169(7):467-473

24. Munn Z, Peters MDJ, Stern C, Tufanaru C, McArthur A, Aromataris E (2018) Systematic review or scoping review? Guidance for authors when choosing between a systematic or scoping review approach. BMC Med Res Methodol 18(1):1-7

25. Peters MDJ, Godfrey CM, Khalil H, McInerney P, Parker D, Soares CB (2015) Guidance for conducting systematic scoping reviews. Int J Evid Based Healthc 13(3):141-146

26. Fantom N, Serajuddin U (2016). The World Bank's classification of countries by income. https://doi.org/10.1596/1813-9450-7528

27. Thomas J, Harden A (2008) Methods for the thematic synthesis of qualitative research in systematic reviews. BMC Med Res Methodol 8:1-10

28. Chao SD, Chang ET, Le PV, Prapong W, Kiernan M, So SKS (2007) The jade ribbon campaign: a model program for community outreach and education to prevent liver cancer in Asian Americans. J Immigr Minor Heal 11(4):281-290

29. Ahmad F, Shakya Y, Li J, Khoaja K, Norman CD, Lou W, et al. A pilot with computer-assisted psychosocial risk -assessment for refugees. BMC Med Inform Decis Mak. 2012;12(1).

30. Casas RN, Gonzales E, Aldana-Aragón E, Del Carmen LaraMuñoz M, Kopelowicz A, Andrews L et al (2014) Toward the early recognition of psychosis among spanish-speaking adults on both sides of the U.S.-Mexico border. Psychol Serv 11(4):460-9

31. Weine S, Kulauzovic Y, Klebic A, Besic S, Mujagic A, Muzurovic J et al (2008) Evaluating a multiple-family group access intervention for refugees with PTSD. J Marital Fam Ther 34(2):149-164

32. Weine SM, Raina D, Zhubi M, Delesi M, Huseni D, Feetham S et al (2003) The TAFES multi-family group intervention for Kosovar refugees: a feasibility study. J Nerv Ment Dis 191(2):100-107

33. White CC, Solid CA, Hodges JS, Boehm DH (2015) Does integrated care affect healthcare utilization in multi-problem refugees? J Immigr Minor Heal 17(5):1444-1450

34. Yeung A, Kung WW, Chung H, Rubenstein G, Roffi P, Mischoulon D et al (2004) Integrating psychiatry and primary care improves acceptability to mental health services among Chinese Americans. Gen Hosp Psychiatry 26(4):256-260

35. Dueweke AR, Bridges AJ (2017) The effects of brief, passive psychoeducation on suicide literacy, stigma, and attitudes toward help-seeking among Latino immigrants living in the United States. Stigma Heal [Internet]. 2(1):28-42

36. Heilemann MV, Soderlund PD, Kehoe P, Brecht M-L (2017) A transmedia storytelling intervention with interactive elements to benefit latinas' mental health: feasibility, acceptability, and efficacy. JMIR Ment Heal [Internet]. 4(4):e47

37. Hernandez MY, Organista KC (2013) Entertainment-education? A fotonovela? A new strategy to improve depression literacy and help-seeking behaviors in at-risk immigrant Latinas. Am J Community Psychol 52(3-4):224-235

38. López SR, Lara M del C, Kopelowicz A, Solano S, Foncerrada H, Aguilera A. (2009) La CLAve to increase psychosis literacy of spanish-speaking community residents and family caregivers. J Consult Clin Psychol 77(4):763-74.

39. Ngo VK, Asarnow JR, Lange J, Jaycox LH, Rea MM, Landon $\mathrm{C}$ et al (2009) Outcomes for youths from racial-ethnic minority groups in a quality improvement intervention for depression treatment. Psychiatr Serv [Internet]. 60(10):1357-64

40. Piwowarczyk L, Bishop H, Saia K, Crosby S, Mudymba FT, Hashi NI et al (2013) Pilot evaluation of a health promotion program for 
African immigrant and refugee women: the UJAMBO program. J Immigr Minor Heal 15(1):219-223

41. Teng EJ, Friedman LC (2009) Increasing mental health awareness and appropriate service use in older Chinese Americans: a pilot intervention. Patient Educ Couns 76(1):143-146

42. Tran AN, Ornelas IJ, Kim M, Perez G, Green M, Lyn MJ et al (2014) Results from a pilot promotora program to reduce depression and stress among immigrant Latinas. Health Promot Pract 15(3):365-372

43. Unger JB, Cabassa LJ, Molina GB, Contreras S, Baron M (2013) Evaluation of a fotonovela to increase depression knowledge and reduce stigma among hispanic adults. J Immigr Minor Heal 15(2):398-406

44. Parrott R (2006) Emphasizing, "Communication" in Health Communication. J Commun [Internet]. 54(4):751-87. https://doi.org/ 10.1111/j.1460-2466.2004.tb02653.x
45. Singhal A, Rogers EM (2002) A theoretical agenda for entertainment-education. Commun Theory 12(2):117-135

46. de Anstiss H, Ziaian T (2010) Mental health help-seeking and refugee adolescents: qualitative findings from a mixed-methods investigation. Aust Psychol 45(1):29-37

47. Wickramage K, Vearey J, Zwi AB, Robinson C, Knipper M (2018) Migration and health: a global public health research priority. BMC Public Health 18(1):1-9

48. Fazel M, Reed RV, Panter-Brick C, Stein A (2012) Mental health of displaced and refugee children resettled in high-income countries: risk and protective factors. Lancet 379(9812):266-282

49. Abebe DS, Lien L, Elstad JI (2017) Immigrants' utilization of specialist mental healthcare according to age, country of origin, and migration history: a nation-wide register study in Norway. Soc Psychiatry Psychiatr Epidemiol 52(6):679-687 